\author{
Military Technical College \\ Kobry El-Kobbah, \\ Cairo, Egypt
}

\author{
$10^{\text {th }}$ International Conference \\ on Electrical Engineering \\ ICEENG 2016
}

\title{
Smart Plastic Bottles Collection Machine Based on the Principle of Gambling Slot Machines
}

\author{
By \\ R. Amro *, R. Qutaineh*, \\ A. Qaud*
}

\section{$\underline{\text { Abstract }}$}

This paper presents the design and implementation of a fully automated plastic bottles collection machine based on the idea of the luck slot machines. However instead of inserting coins, our machine accepts only empty plastic bottles. Once the inserted item is accepted by the machine, three wheels with fruit logos start to rotate. After the rotation times are over and in case that the three wheels stop at similar fruit logo the user wins.

\section{Keywords}

Recycling, Plastic Bottles, Microcontroller, Slot machines

* Palestine Polytechnic University 


\section{Introduction:}

Due to its low-cost, lightweight and corrosion resistivity plastic is increasingly used in several applications like packaging . The production of plastic has increased from 0,5 million tonnes in 1950 to more than 260 millions tones today [1] [2].

The in the plastic included polymers are not water-soluble and unable to pass through cell membranes of micro organisms. That leads to very long degradation process and make the increased plastic utilization to a real challenge for our environment. Therefore recycling efforts and initiatives must be motivated and supported.

Our machine aims to motivate people to through the used plastic bottles in specific place as first step for recycling process. The machine accepts only empty plastic bottles. None-plastic items like wood or cartoons or un-empty plastic bottles will be detected and thrown out of the machine.

The idea depends on using the excitation feeling of humans to win similar to the principle of the gambling "Slot Machine". However instead of inserting money coins, our green luck machine is activated by empty plastic bottles ready for recycling. Our machine can be placed with intensive human traffic like malls, universities and schools Figure 1 shows a photography of our machine (left) and a real gambling slot machine (right)
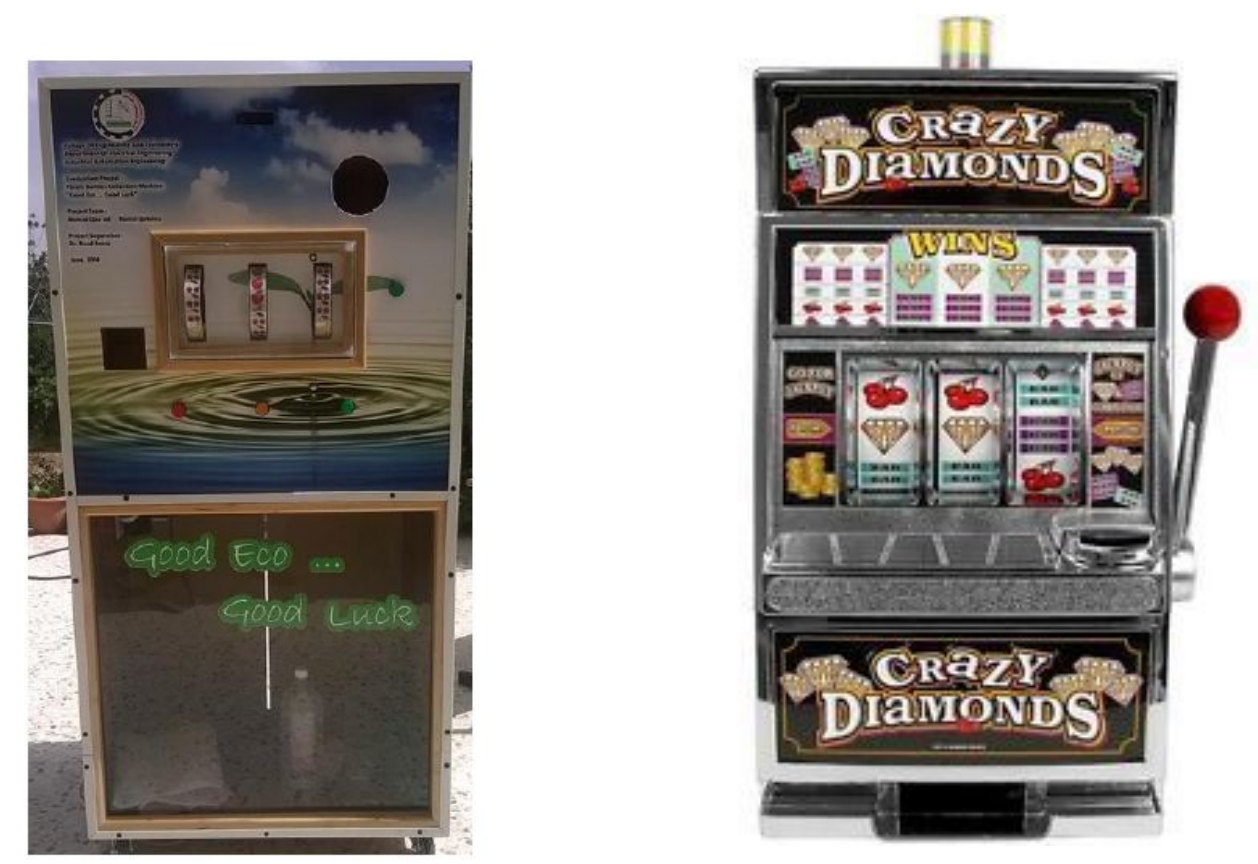

Figure (1): A photography of our machine (left) and of real slot machine (right) 


\section{$\underline{\text { 2. Construction }}$}

\section{a) Mechanical Design}

In sake of flexibility in moving the machine and electrical safety considerations we decided to build the prototype using mainly MDF wood. Its dimensions are $150 \mathrm{~cm} \mathrm{X}$ $80 \mathrm{~cm}$ X $60 \mathrm{~cm}$ (Length X Width X Depth).

The upper part of the machine contains:

The electrical components installations and a hole for inserting the bottles (not obvious for the user)

- A hole for inserting the bottles (obvious for the user)

- Three luck wheels with fruits logos

- LCD monitor for messages to the user

- Win-coupon receiving window

- Three lamps (Red, Orange and Green) to signalize the operation status

The bottom part of the machine is a movable container for the accepted bottles with transparent cover. The container has place for ca. 300 a 2 Liter bottles.

Figure 2 shows the general construction of the machine

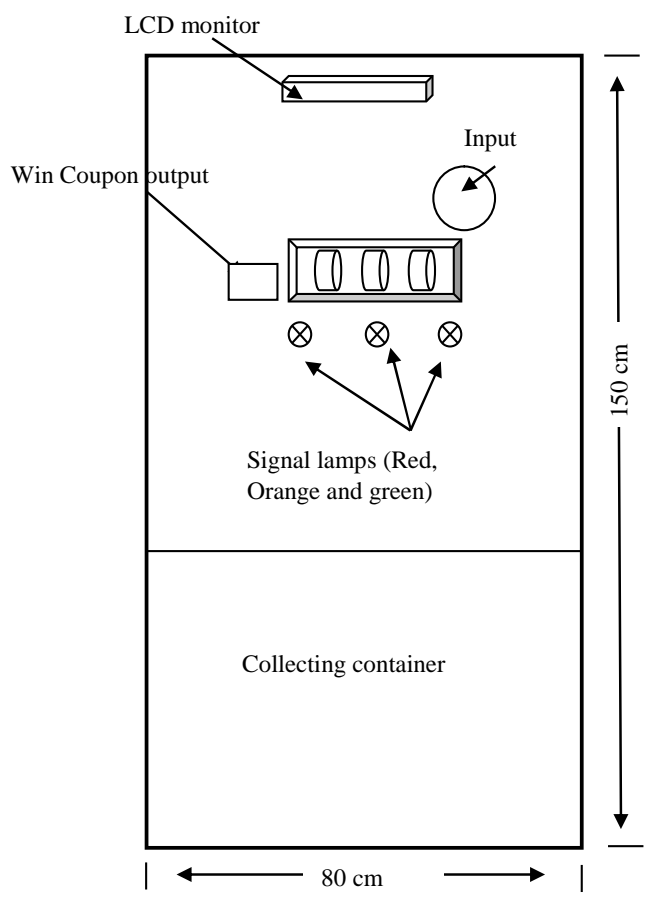

Figure (2): Front -view and dimensions of the prototype 


\section{b) Electrical Components}

- Sensors: We used two types of sensors to accomplish three different functions:

1) Proximity Sensors: Proximity sensors are used to detect the presence of objects by sending of electromagnetic waves and detecting any changes in their reflection. Such sensors are needed in our machine to firstly detect the presence of item and this sensor is placed directly after the Input (see Fig.2). Secondly six proximity sensors are used to determine whether the three wheels stop at similar fruit logo (win case) or not. The algorithm for this function will be described later in Control Concept section.

We used Arduino proximity sensor as shown in Figure 3

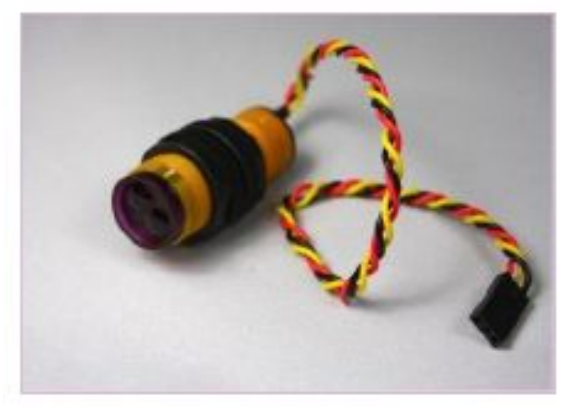

Figure (3): Proximity Sensor

2) Capacitive Proximity Sensor: This sensor is used to detect whether the inserted item is purely plastic with no content (empty). We used the in Figure 4 shown EFFECTOR K 15065 capacitive sensor [3].

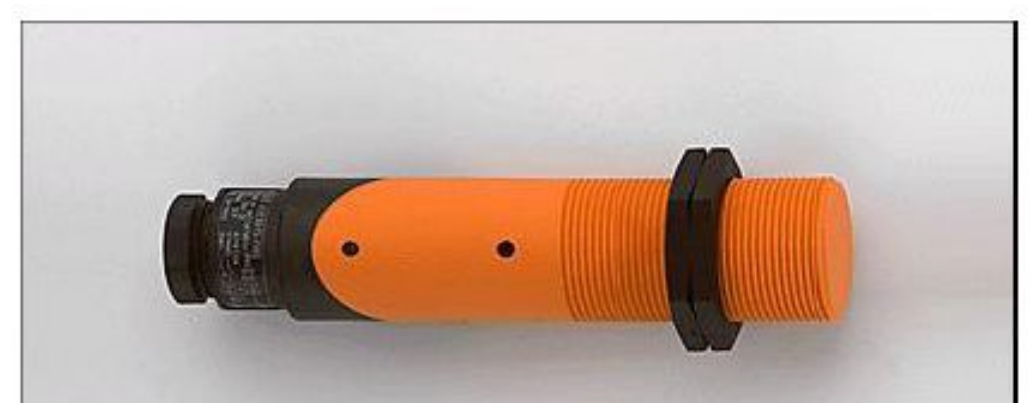

Figure (4): Capacitive Proximity Sensor 
- Electrical Motors: Six small permanent, Direct Current (DC) motors are needed in our 'project. A $12 \mathrm{~V} \mathrm{DC}$ motor is used to throw out any unaccepted items inserted via the input and also a $12 \mathrm{~V}$ DC motor is used to transport the accepted bottles to the collecting container. The third motor is used to slide out the win coupon in case of three similar logos. Three DC motors are needed rotate the luck wheels [4].

- Power Supply Unit :is used to transform the domestical $220 \mathrm{~V} \mathrm{AC} \mathrm{into} 6 \mathrm{~V}$ DC for the

- The Microcontroller: to automate the whole process we used the in Fig.5 illustrated AT Mega 1280 microcontroller with 54 digital inputs and outputs [5]

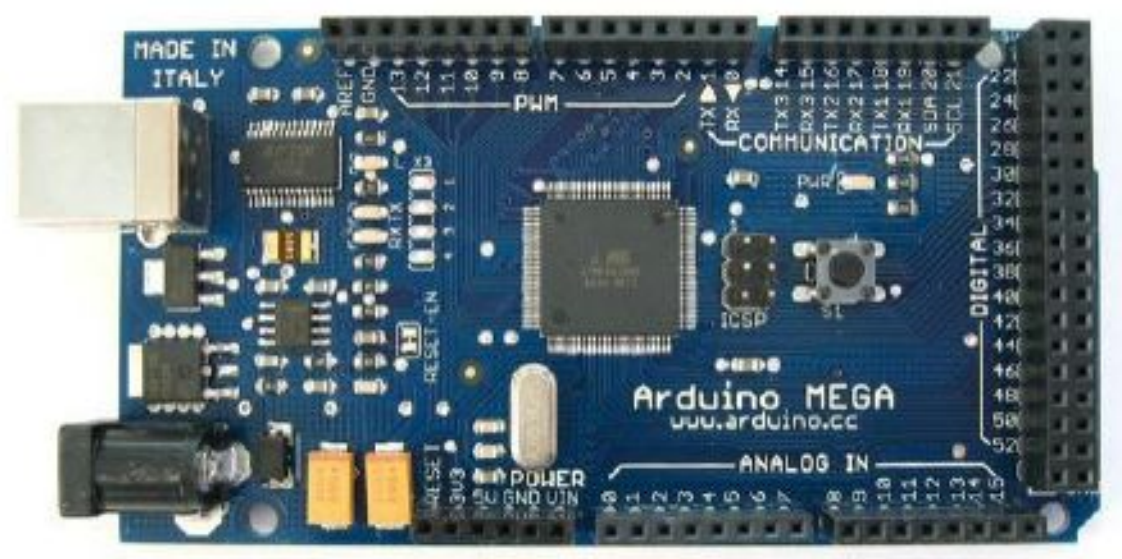

Figure (5): Microcontroller (AT MEGA 1280

\section{Operational Principle and Control Concept}

The detection of presence of inserted item and whether this item is acceptable or not follow with the help of proximity sensors which send the respective signal to the microcontroller. The micro-controller activates then DC motors to activate the rotation of the luck wheels and transport the plastic bottles to the collecting container. Also with help of DC motors invalid inserted items (like wooden items or glass bottles) will be thrown out of the machine. The following Figure6 shows a schematic of the used microcontroller with the connected inputs and outputs. 


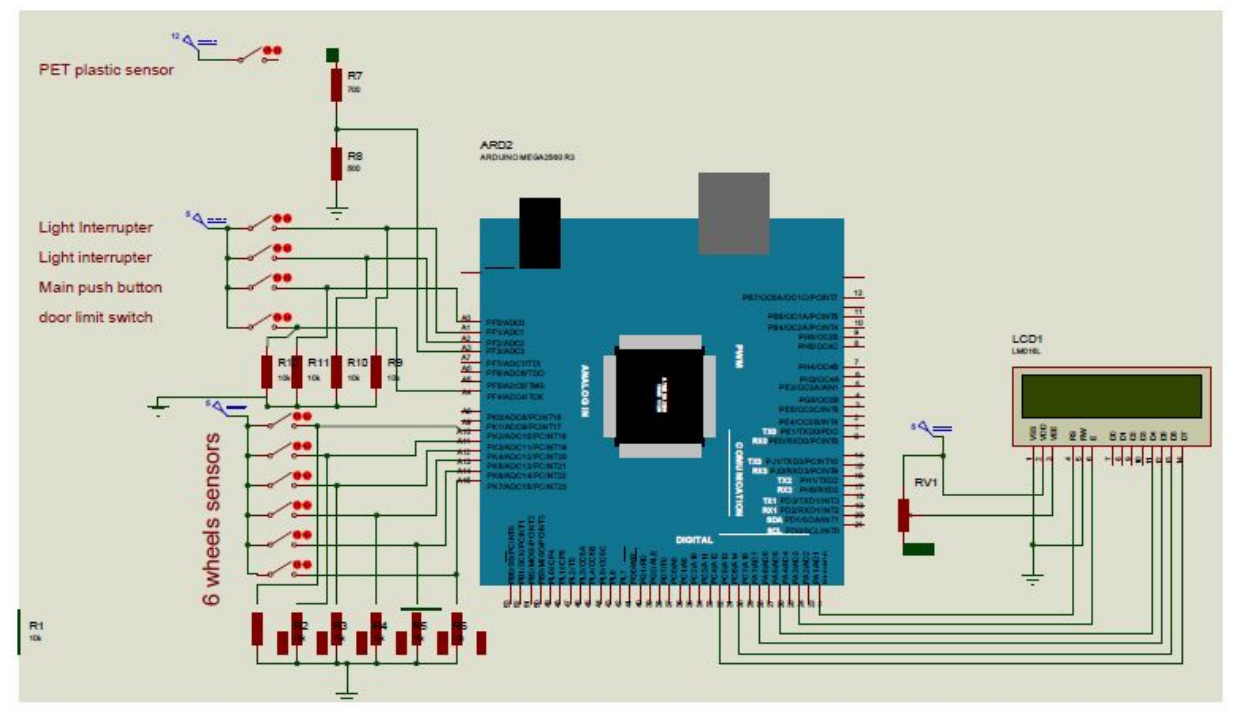

Figure (6): Connections of the Microcontroller with the Outputs and Inputs (AT MEGA 1280)

The detailed control procedure is described in details using the flowchart shown in Figure 8. on the next page.

We used three different fruit logos (Banana, Cherries and Apple). To determine whether the three wheels stop at similar logo (win case) we used the following procedure:

- Each wheel has two proximity sensors

- We made at each wheel two holes behind two different fruit logos as shown in Figure 7

- Each sensor gives the logic signal "1" if it detects a hole and "0" in the other case. All sensor signal are sent to the microcontroller.

- We have three similar logos only in the three sensor readings shown in following Table 1. 
Table (1): Logic states in case of 3 similar logos (win Case)

\begin{tabular}{|l|l|l|l|} 
Sensor Nr & Logic State 1 & Logic State 2 & Logic State 2 \\
\hline 1 & 1 & 1 & 0 \\
\hline 2 & 0 & 1 & 1 \\
\hline 3 & 0 & 1 & 1 \\
\hline 4 & 1 & 0 & 1 \\
\hline 5 & 1 & 0 & 1 \\
\hline 6 & 1 & 1 & 0 \\
\hline & Three Apples & $\begin{array}{l}\text { Three } \\
\text { Cherries }\end{array}$ & $\begin{array}{l}\text { Three } \\
\text { Bananas }\end{array}$ \\
\hline
\end{tabular}

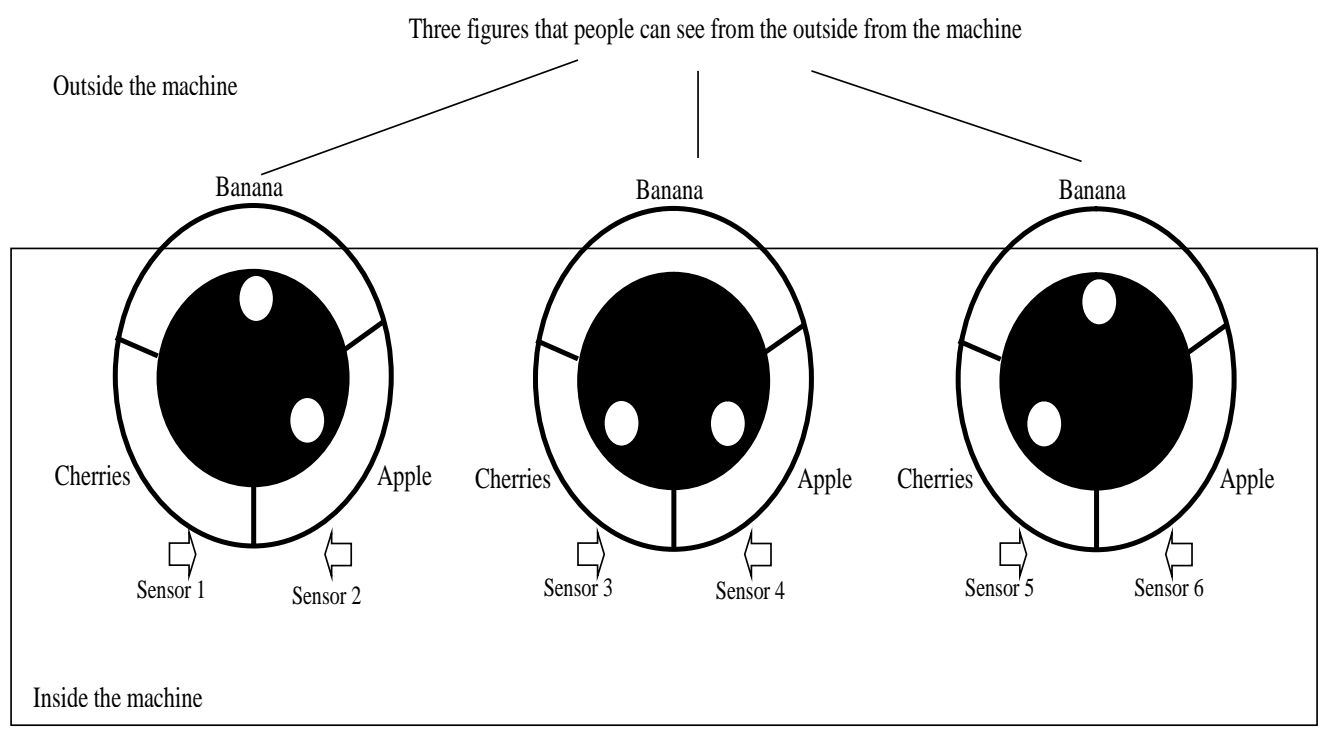

Figure (7): Hardware to determine "Win" or "Good Luck" cases 


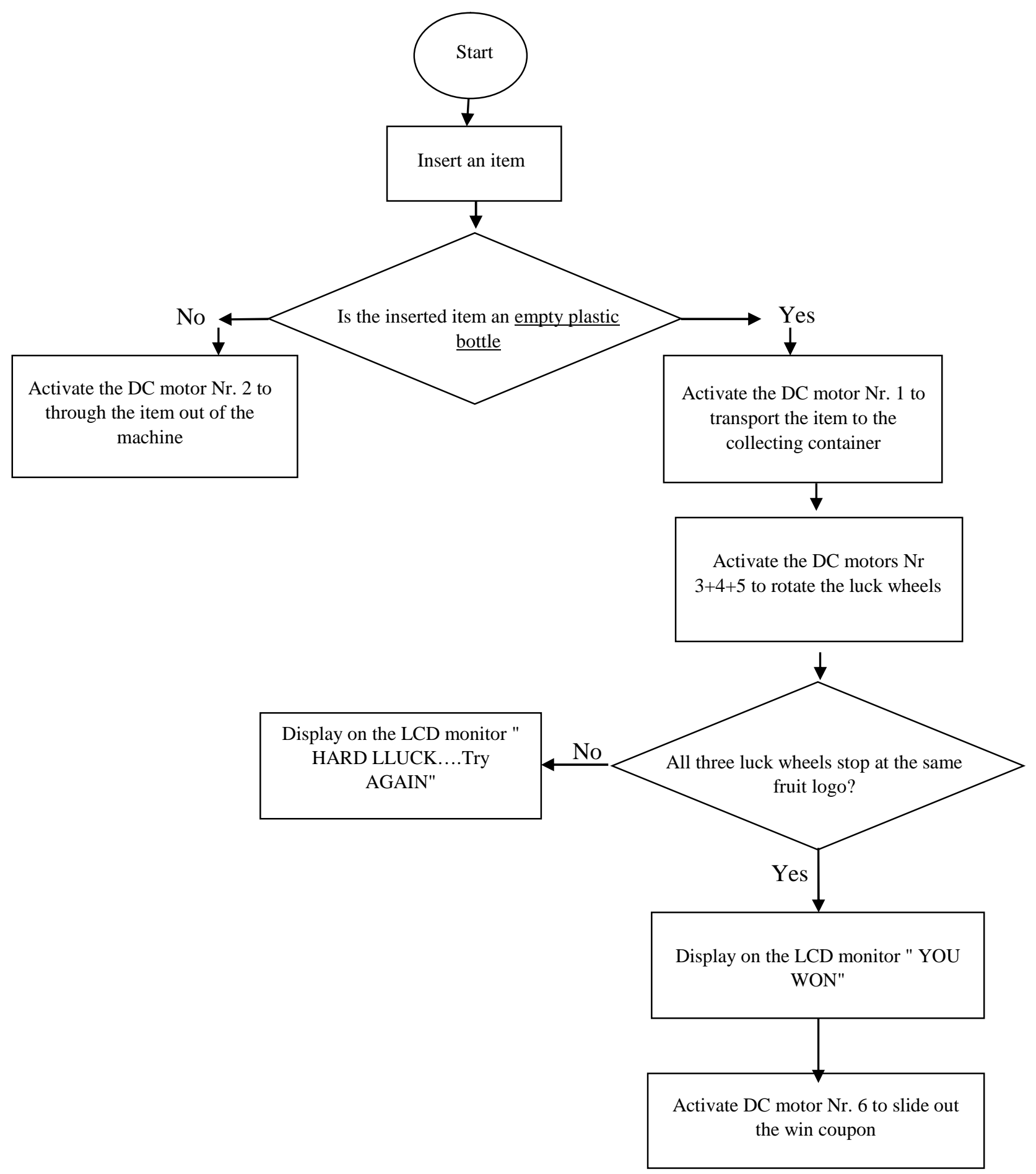

Figure (8) : Flow Chart of the operational principle 


\section{Conclusion}

We designed and built a prototype for a plastic bottle collection machine. The machine uses the principle of the gambling slot machine. However, our machine accepts only recyclable plastic bottles instead of coins. It is accepted that the excitation feeling of win will motivate the people to dispose the plastic bottles in predefined places as first step to their recycling.

It is worthy to underline that and for a successful application of the idea a complete recycling process after the collection of the items is necessary.

\section{References}

[1] Richard C Thompson, Charles J. Moore, Frederik S. von Saal, Shanna H. Swan: On Plastic, Human and Environment: Current Concerns and Future Trends

[2] The Cambridge MIT Institute, University of Cambridge: Restyling of Plastic

[3] Peter Elgar: Sensors and Transducers

[4] Hundmarsch J. : Electrical Machines and Their Applications

[5] Moudgalya- Kannan: Digital Control 